\title{
Synthesis and Properties of Highly Branched Polycations with an Aliphatic Polyether Scaffold
}

\author{
ERNST SCHWAB, STEFAN MECKING \\ Fachbereich Chemie, Universität Konstanz, Universitätsstraße 10, 78457 Konstanz, Germany
}

\begin{abstract}
Cationic polyelectrolytes with pyridinium and 1,2-dimethylimidazolium functionalities based on a hyperbranched polyglycerol scaffold with a narrow polydispersity were prepared by a polymer analogous reaction in a one-pot synthesis. By the variation of the spacer lengths between the cationic functionalities and polyether scaffold, a simple method was developed to adjust the charge density and flexibility of the polycations, as reflected by their glass-transition temperature. The polyelectrolytes were further characterized in detail by ${ }^{1} \mathrm{H} N M R,{ }^{13} \mathrm{C} \mathrm{NMR}$, and IR spectroscopy, as well as thermogravimetric analysis.
\end{abstract}

Keywords: functionalization of polymers; hyperbranched; polyelectrolytes

\section{INTRODUCTION}

The field of dendritic polymers, that is, dendrimers $^{1-5}$ and hyperbranched polymers, ${ }^{6-11}$ has found widespread interest in the past decade. In addition to noncharged polymers, highly branched polyelectrolytes have also found strong interest. ${ }^{12-17}$ The prime example of a highly branched polyelectrolyte is polyethyleneimine. Its properties in aqueous solutions strongly vary with the $\mathrm{pH}$-dependent charge, which is decisive in applications. ${ }^{18-20}$ The properties of charged branched topologies are also of considerable theoretical interest. $^{21-24}$ Our interest in hyperbranched polyelectrolytes stems from the concept of noncovalent binding of catalytically active metal complexes to soluble polymers by electrostatic interactions, with the aim of recovering and recycling such catalysts by means of ultrafiltration. ${ }^{25-28}$ For this purpose and also other fundamental studies and potential applications, the synthesis

Correspondence to: S. Mecking (E-mail: stefan.mecking@ uni-konstanz.de) of well-defined and at the same time easily accessible highly branched polyelectrolytes is desirable. Particularly for catalysis, polymeric supports that are soluble in organic solvents (as opposed to water) are required most often. Hyperbranched polyglycerol can be prepared on a kilogram scale with narrow molecular weight distributions by the anionic ring-opening polymerization of glycidol. ${ }^{29-31}$ Consisting of an inert polyether scaffold and a large number of reactive $\mathrm{OH}$ groups, it is a convenient starting material for the synthesis of functionalized polymers with a hyperbranched scaffold. ${ }^{32-34}$ In this article, we report on the synthesis of hyperbranched polyglycerol-based polycations.

\section{RESULTS AND DISCUSSION}

\section{Synthesis and Characterization}

Cationic polyelectrolytes with pyridinium and 1,2-dimethylimidazolium (1,2-DMI) functionalities were prepared by polymer analogous functionalization of hyperbranched polyglycerol. The 

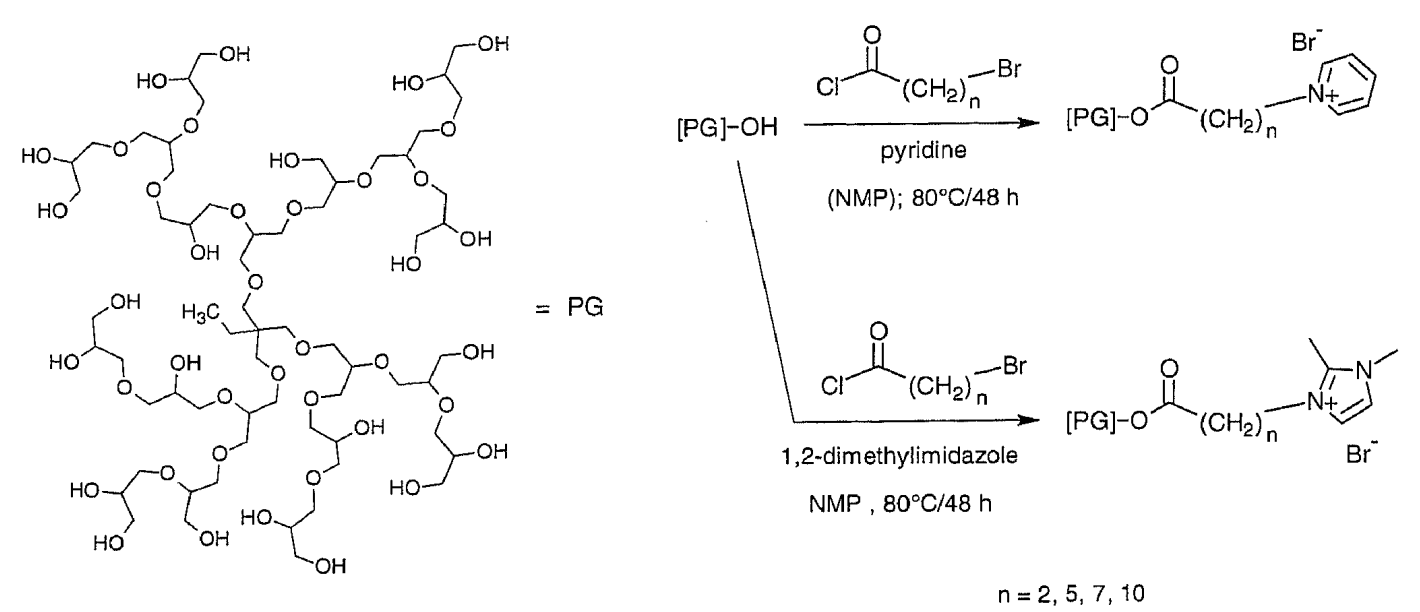

Scheme 1. Synthesis of the hyperbranched pyridinium and imidazolium polycations.

polyglycerol used in this work had a number-average molecular weight $\left(M_{\mathrm{n}}\right)$ of $6000 \mathrm{~g} / \mathrm{mol}$ (determined by ${ }^{13} \mathrm{C} N M R$ ) and a polydispersity (weightaverage molecular weight/number-average molecular weight) of 1.5 [determined by size exclusion chromatography vs poly(propylene oxide) standards]. The molecular mass corresponded to an average degree of polymerization $\left(\mathrm{DP}_{\mathrm{n}}\right)$ of 80 , which is approximately equivalent to the number of hydroxy groups (when the core functionality is neglected. The number of hydroxy groups is precisely $\mathrm{DP}_{\mathrm{n}}+3, \mathrm{DP}_{\mathrm{n}}$ corresponding to the monomer units added).

The well-known reaction of nitrogen-containing heterocycles or amines with alkyl halides to form alkyl ammonium salts ${ }^{35}$ was used for the synthesis of polyelectrolytes with pyridinium and 1,2-DMI functionalities. Esterification has proven to be a versatile reaction for the functionalization of polyglycerols. ${ }^{32}$ Reacting $\omega$-bromoacyl chlorides with polyglycerol in the presence of pyridine or 1,2-DMI allows for the functionalization of the polyglycerol scaffold and the generation of the cationic moieties by quaternization simultaneously in a one-pot reaction (Scheme 1). The variation of the nature of the cationic group, the spacer length, and the control of the degree of functionalization allows for the synthesis of polycations with a variable charge density and flexibility.

\section{Pyridinium Polyelectrolytes}

The synthesis of pyridinium polyelectrolytes was carried out in neat pyridine as a solvent, in which polyglycerol possesses good solubility. To ensure complete functionalization, a slight excess of $\omega$ bromoacyl chloride (1.05 equiv to $\mathrm{OH}$ ) was used. The esterified polyglycerol, as well as the result- ing polyelectrolyte, possessed low solubility in pyridine and precipitated during the reaction. This hampered a complete conversion of the functional groups. At temperatures around $80{ }^{\circ} \mathrm{C}$, a sufficient mixing of the viscous reaction media was ensured, but reaction times of at least $48 \mathrm{~h}$ were required for complete conversion, as representatively shown in Table 1 for the synthesis of $\mathrm{PG}\left(\mathrm{C}_{5}-\mathrm{pyr}-\mathrm{Br}\right)_{1.0}$ [general nomenclature for the designation of polyelectrolytes: $\mathrm{PG}$ (spacer lengthcationic moiety-counterion) (degree of functionalization: $1.0=100 \%)]$.

Whereas the esterification proceeded more rapidly, the quaternization required 2 days of reaction at $80^{\circ} \mathrm{C}$ for complete conversion. After purification via dialysis, the polycations could be isolated in yields around $90 \%$.

As expected, the degree of functionalization and thus the charge density can be controlled by the stoichiometry of the acyl chloride. For various polyelectrolytes with different degrees of functionalization, the experimentally observed composition of the products coincides well within experimental error with the theoretical degrees of func-

Table 1. Degrees of Functionalization with Time for the Synthesis of $\mathrm{PG}\left(\mathrm{C}_{5}-\mathrm{pyr}-\mathrm{Br}\right)_{1.0}{ }^{\mathrm{a}}$

\begin{tabular}{ccc}
$\begin{array}{c}\text { Reaction } \\
\text { Time }(\mathrm{h})\end{array}$ & $\begin{array}{c}\text { Degree of } \\
\text { Esterification }(\%)^{\mathrm{b}}\end{array}$ & $\begin{array}{c}\text { Degree of } \\
\text { Quaternization }(\%)^{\mathrm{b}}\end{array}$ \\
\hline 6 & 93 & 60 \\
17 & 97 & 83 \\
50 & 96 & 98 \\
\hline
\end{tabular}

a Reaction conditions: $3 \mathrm{~g}$ of polyglycerol $(40 \mathrm{mmol}$ of $\mathrm{OH}), 42 \mathrm{mmol}$ of 6-bromo-hexanoyl chloride in $45 \mathrm{~mL}$ of pyridine, and a reaction temperature of $80^{\circ} \mathrm{C}$.

${ }^{\mathrm{b}}$ Determined from ${ }^{1} \mathrm{H}$ and ${ }^{13} \mathrm{C}$ NMR spectra. 
Table 2. Degrees of Functionalization $(x)$ of Polyelectrolytes $\mathrm{PG}\left(\mathrm{C}_{5}-\mathrm{pyr}-\mathrm{Br}\right)_{x}$

\begin{tabular}{lccl}
\hline Polyelectrolyte & Theoretical & Esterification & $\begin{array}{c}x \text { Experimental }^{\mathrm{a}} \\
\text { Quaternization }\end{array}$ \\
\hline $\mathrm{PG}\left(\mathrm{C}_{5}-\mathrm{pyr}-\mathrm{Br}\right)_{0.3}$ & 0.30 & $27 \%$ & $100 \%$ (with respect to esterification) \\
$\mathrm{PG}\left(\mathrm{C}_{5}-\mathrm{pyr}-\mathrm{Br}\right)_{0.5}$ & 0.57 & $52 \%$ & $98 \%$ (with respect to esterification) \\
$\mathrm{PG}\left(\mathrm{C}_{5}-\mathrm{pyr}-\mathrm{Br}\right)_{0.7}$ & 0.70 & $67 \%$ & $99 \%$ (with respect to esterification) \\
\hline
\end{tabular}

"Determined by ${ }^{1} \mathrm{H}$ NMR spectroscopy.

tionalization calculated from the ratio of reagents employed (Table 2).

In the aforementioned approach, depending on the degree of functionalization, a certain portion of unreacted $\mathrm{OH}$ groups remains. With the polyelectrolytes employed as catalyst supports, these remaining $\mathrm{OH}$ groups can result in undesired side reactions. Another possibility for adjusting the charge density of the polycations is the variation of spacer length $n$ (see Scheme 1). To this end, $\omega$ bromoacyl chlorides with alkyl spacers with 2,7 , and $10 \mathrm{C}$ atoms were employed.

The syntheses of pyridinium polyelectrolytes with spacers $\mathrm{C}_{7}$ and $\mathrm{C}_{10}$ were carried out in the same way as the synthesis of $\mathrm{PG}\left(\mathrm{C}_{5}-\mathrm{pyr}-\mathrm{Br}\right)_{1.0}$. A different protocol was required for the synthesis of $\mathrm{PG}\left(\mathrm{C}_{2}-\mathrm{pyr}-\mathrm{Br}\right)_{1.0}$. As 3-bromopropionyl chloride reacts spontaneously with pyridine, this reaction was carried out in two steps. Polyglycerol was first reacted with the acyl chloride in $N$-methylpyrrolidone (NMP) at room temperature. After
2-3 h, a 3-4-fold (with respect to $\mathrm{OH}$ groups) excess of pyridine was added, and the reaction mixture was stirred for 2 days at $80-90{ }^{\circ} \mathrm{C}$.

In all cases, complete conversions with respect to esterification as well as quaternization were observed for the syntheses of pyridinium polyelectrolytes with spacer lengths of $2,5,7$, and $10 \mathrm{C}$ atoms, with yields up to $90 \%$.

\section{Spectroscopic Characterization}

The degree of functionalization (esterification and quaternization) was determined by ${ }^{1} \mathrm{H}$ NMR spectroscopy. A representative ${ }^{1} \mathrm{H}$ NMR spectrum of the polyelectrolyte $\mathrm{PG}\left(\mathrm{C}_{5}-\mathrm{pyr}-\mathrm{Br}\right)_{1.0}$ is shown in Figure 1.

The proton signals of the pyridinium group appear at 8.1-9.4 ppm, and those of the aliphatic spacers appear between 1.4 and $2.4 \mathrm{ppm}$. The methylene protons adjacent to the pyridinium unit give rise to a signal at $4.8 \mathrm{ppm}$.

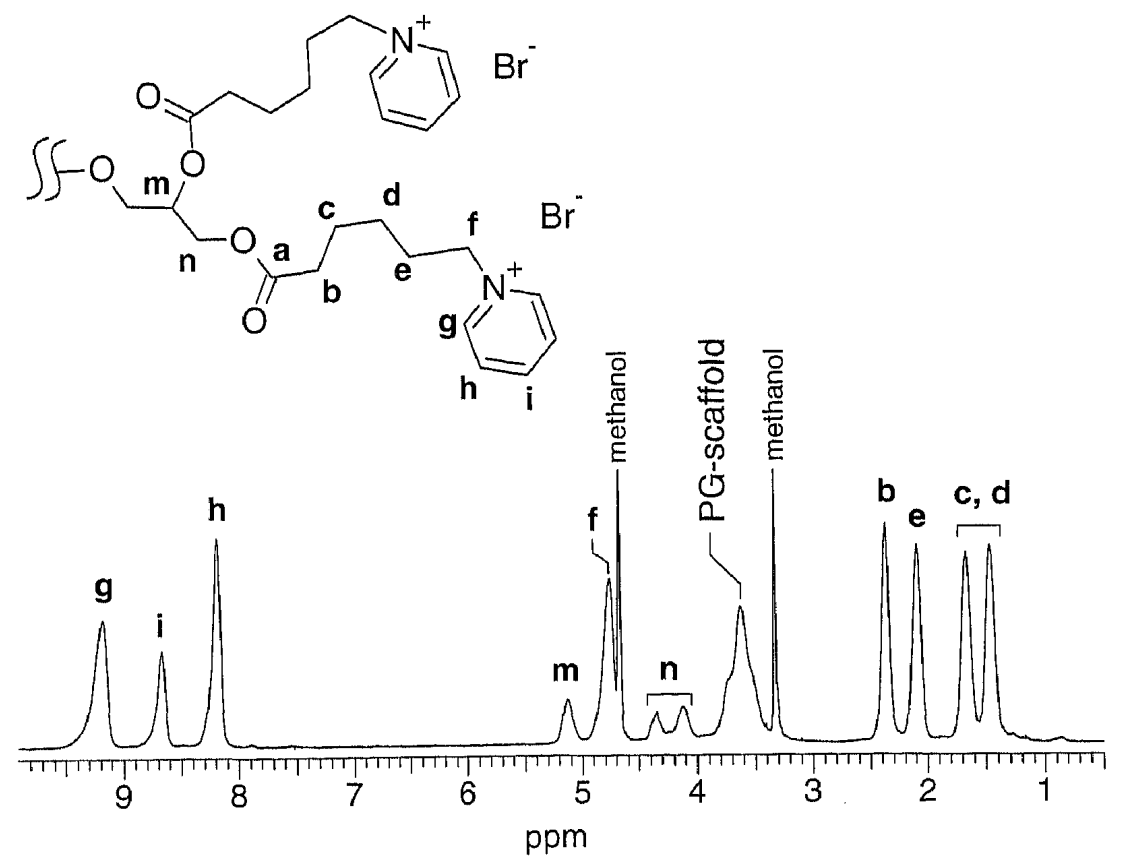

Figure 1. ${ }^{1} \mathrm{H}$ NMR (methanol- $d_{4}, 300 \mathrm{MHz}$ ) spectrum of the polyelectrolyte $\mathrm{PG}\left(\mathrm{C}_{5}-\right.$ pyr-Br) $)_{1.0}$. 


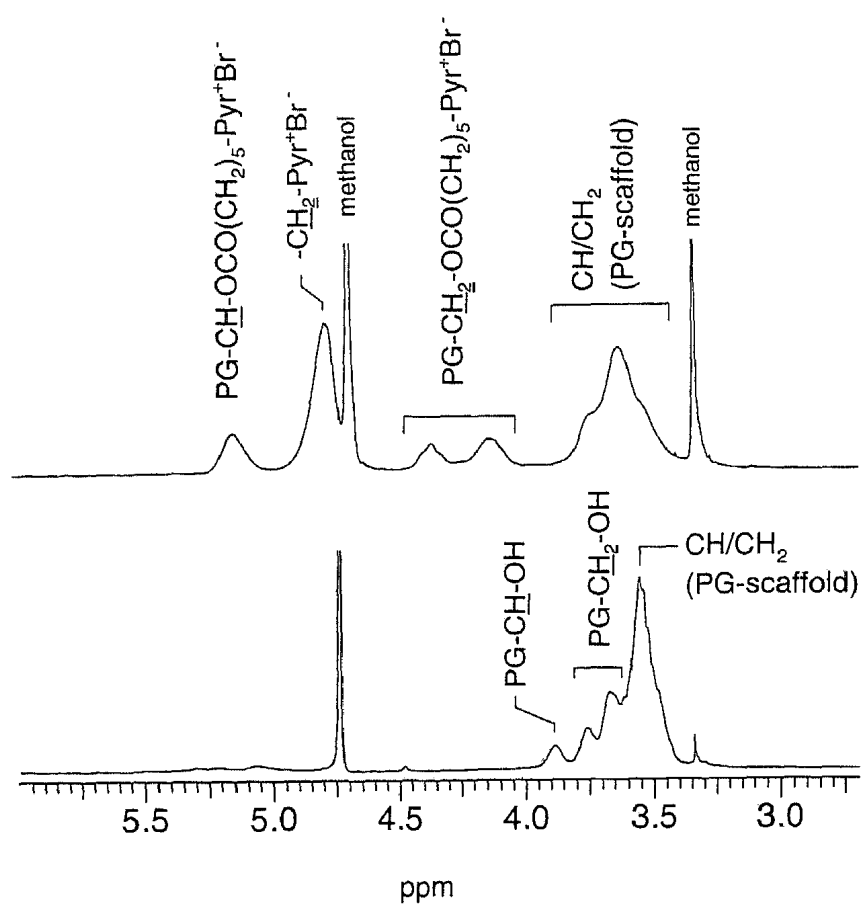

Figure 2. Comparison of the sections from 2.7-6 ppm of the ${ }^{1} \mathrm{H}$ NMR spectra of $\mathrm{PG}\left(\mathrm{C}_{5}-\mathrm{pyr}-\mathrm{Br}\right)_{1.0}$ (top) and unfunctionalized polyglycerol (bottom).

A comparison with the ${ }^{1} \mathrm{H}$ NMR spectrum of unfunctionalized polyglycerol (Fig. 2) shows a clear shift of the methine proton signals of the esterified secondary hydroxyl group, which can be assigned to the signal at $5.2 \mathrm{ppm}$.

The methylene protons of the esterified hydroxyl groups resonate at 4.1 and $4.3 \mathrm{ppm}$. Because of their diastereotopic nature, they appear as two distinct signals. As expected, the other methine and methylene protons of the polyglycerol scaffold deviate only to a small extent from the spectrum of unmodified polyglycerol, resonating as a broad signal at 3.3-3.7 ppm.

${ }^{1} \mathrm{H}$ NMR spectra of the polyelectrolytes with $\mathrm{C}_{7}$ and $\mathrm{C}_{10}$ spacers are similar to the spectrum of $\mathrm{PG}\left(\mathrm{C}_{5}-\mathrm{pyr}-\mathrm{Br}\right)_{1.0}$ shown in Figure 1, differing only in the region of the alkyl signals at 1.6$1.1 \mathrm{ppm}$. As expected, the methylene protons of the spacer of $\mathrm{PG}\left(\mathrm{C}_{2}-\mathrm{pyr}-\mathrm{Br}\right)_{1.0}$ resonate at a lower field in comparison with those of the other polyelectrolytes. The signals of the $-\mathrm{CH}_{2}-\mathrm{N}^{+}$ group overlie the methine signals at $5.2 \mathrm{ppm}$. The other methylene group of the spacer resonates at $3.3 \mathrm{ppm}$. In all cases, the proton signals of unreacted hydroxyl groups were not detected in dimethyl sulfoxide (DMSO).

The Fourier transform infrared (FTIR) spectra are in accordance with expectations, the most prominent signal being the strong $\mathrm{C}=\mathrm{O}$ absorbance of the ester groups at $1728 \mathrm{~cm}^{-1}$ [value for $\left.\mathrm{PG}\left(\mathrm{C}_{5}-\mathrm{pyr}-\mathrm{Br}\right)_{1.0}\right]$.

\section{1,2-DMI Polyelectrolytes}

The polyelectrolytes with 1,2-DMI functionalities were prepared similarly to the aforementioned synthesis of $\mathrm{PG}\left(\mathrm{C}_{2}-\mathrm{pyr}-\mathrm{Br}\right)_{1.0}$. Polyglycerol possesses low solubility in 1,2-dimethylimidazole; thus, the reaction was performed in NMP. Polyglycerol was first esterified with $\omega$-bromoacyl chloride; after about 2-3 h, an excess of 1,2-DMI was added at $80^{\circ} \mathrm{C}$, and the mixture was stirred for 2 days. Like the pyridinium polyelectrolytes, the resulting polycation was not soluble in the reaction mixture and precipitated as a viscous solid. Polyelectrolytes with spacer lengths of 2,5 , 7 , and $10 \mathrm{C}$ atoms were synthesized. In all cases, the reaction resulted in full conversion with respect to esterification and quaternization, affording the final product in an $80-90 \%$ yield after purification by dialysis.

\section{Spectroscopic Characterization}

${ }^{1} \mathrm{H}$ NMR spectra of polyelectrolytes with $1,2-$ dimethyl imidazolium bromide end groups deviate from the spectra of pyridinium polyelectrolytes only by the resonance signals of the cationic group, as expected. The methylene protons of the spacer adjacent to the cationic group give rise to a signal at $4.2 \mathrm{ppm}$ [in comparison with $4.4 \mathrm{ppm}$ for $\left.\mathrm{PG}\left(\mathrm{C}_{2}-1,2-\mathrm{DMI}-\mathrm{Br}\right)_{1.0}\right]$. The proton signals of the imidazolium $\mathrm{C}-\mathrm{C}$ double bond occur as a broad doublet at 7.5-7.7 ppm. The methyl groups resonate at $3.85\left(\mathrm{~N}-\mathrm{CH}_{3}\right)$ and $2.70 \mathrm{ppm}\left(\mathrm{C}-\mathrm{CH}_{3}\right)$, respectively.

FTIR spectra of $\mathrm{PG}\left(\mathrm{C}_{5}-1,2-\mathrm{DMI}-\mathrm{Br}\right)_{1.0}$ feature absorbance bands at 1587, 1539, and $1458 \mathrm{~cm}^{-1}$, which were assigned to the $\mathrm{C}=\mathrm{C}, \mathrm{C}=\mathrm{N}$, and $\mathrm{C}-\mathrm{N}$ vibrational resonances of the 1,2-DMI group.

\section{Synthesis of Other Polyelectrolytes}

To enhance the solubility of the polyelectrolytes in organic solvents, the incorporation of aliphatic amines, namely triethylamine and tributylamine, instead of the aforementioned N-heterocycles was investigated. However, the synthesis of polycations with alkylammonium end groups by the aforementioned procedure resulted only in limited conversions with respect to quaternization. Whereas full esterification of the $\mathrm{OH}$ groups of the polyglycerol 


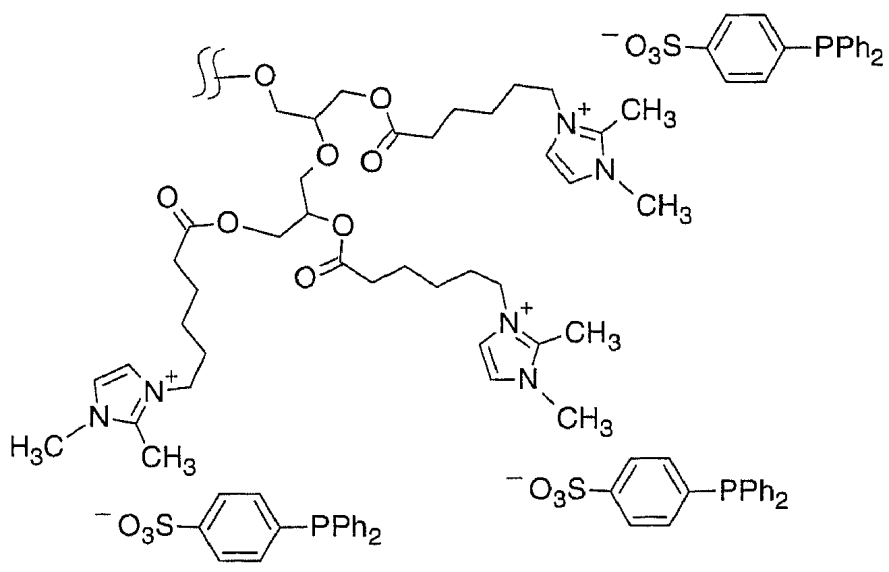

Figure 3. Structure of $\mathrm{PG}\left(\mathrm{C}_{5}-1,2-\mathrm{DMI}-\mathrm{TPPMS}\right)_{1.0}$.

scaffold was achieved, only incomplete quaternization was observed even after long reaction times of more than 5 days. A decrease in the degree of quaternization with increasing length of the amine alkyl chains was observed, the quaternization with triethylamine reaching a maximum of $60 \%$ conversion according to ${ }^{1} \mathrm{H} /{ }^{13} \mathrm{C}$ NMR measurements in comparison with $30 \%$ for tributylamine.

Whereas in studies on hydroformylation the polyelectrolytes have proven to be inert supports ${ }^{26}$ for catalysis in general and for long-term stability, the exclusion of ester groups, which can be hydrolyzed, is of interest. To this end, the reaction of polyglycerol with methanesulfonyl chloride resulted in a polymer with methanesulfonate end groups. The substitution of the sulfonate leaving groups by, for example, 1,2-dimethylimidazole resulted in a polyelectrolyte in which the cationic functionalities were directly attached to the polyether scaffold. However, ${ }^{13} \mathrm{C}$ NMR spectroscopic analyses revealed that only about $50 \%$ of the $\mathrm{OH}$ groups had been functionalized, with $85 \%$ of the terminal primary $\mathrm{OH}$ groups and $25 \%$ of the secondary $\mathrm{OH}$ groups having been converted. With 4-toluenesulfonyl chloride, more than $92 \%$ of the $\mathrm{OH}$ groups were tosylated, but no quaternization occurred with pyridine.

\section{Counterion Exchange}

In view of their utilization as catalyst supports, $p$ (diphenylphosphino)benzene sulfonate (TPPMS) was introduced as a counterion into the polyelectrolytes by exchange for the halogen counterions (Fig. 3).

The dropwise addition of an aqueous solution of PG(C $\left.\mathrm{C}_{n}-1,2-\mathrm{DMI}-\mathrm{Br}\right)_{1.0}$ to an aqueous solution of 1.05 ionic equiv of potassium 4-(diphenylphosphino)benzene sulfonate (KTPPMS) at $80{ }^{\circ} \mathrm{C}$ resulted in the complete exchange of counterions, the polyelectrolyte $\mathrm{PG}\left(\mathrm{C}_{n}-1,2-\mathrm{DMI}-\mathrm{TPPMS}\right)_{1.0}$ precipitating at the end of the addition. Workup by washing twice with water or alternatively purification by dialysis in methanol yielded the polyelectrolyte in yields of 70-90\% (the yields varied largely because of the different water solubility of the particular polyelectrolyte).

\section{Solubility}

As expected, the synthesized polyelectrolytes based on pyridinium and 1,2-DMI groups with halide counterions possess high solubility $(>300$ $\mathrm{g} / \mathrm{L})$ in water. They are also soluble in methanol, dimethylformamide, and DMSO and insoluble in other organic solvents such as acetone, tetrahydrofuran, $\mathrm{CH}_{2} \mathrm{Cl}_{2}$, and less polar solvents. The variation of the alkyl spacer length in the range of 2-10 C atoms has little influence on their solubility. The exchange of the bromide ions by TPPMS leads to polyelectrolytes that are insoluble in water but soluble in some polar organic solvents such as dichloromethane and methanol.

The solution viscosity was investigated preliminarily by capillary viscosimetry in salt-free aqueous solutions and $0.1 \mathrm{M} \mathrm{KBr}$ for $\mathrm{PG}\left(\mathrm{C}_{5}-1,2\right.$ $\mathrm{DMI}-\mathrm{Br})_{1.0}$ at concentrations in the range of $10^{2}$ to $5 \times 10^{-1} \mathrm{~g} / \mathrm{L}$. In salt-free solutions, a typical polyelectrolyte effect (well known for linear and dendritic structures ${ }^{12,17,36}$, that is, a strong increase in the reduced viscosity with decreasing concentration, was observed.

\section{Thermal Behavior}

The thermal behavior of the hyperbranched polyelectrolytes was investigated by differential scanning calorimetry (DSC) with respect to the degree of functionalization, length of the alkyl spacer, and nature of the counterions (Table 3). The highly hygroscopic nature of all the polymers required careful drying $\left(48 \mathrm{~h}\right.$ at $80{ }^{\circ} \mathrm{C}$ and $0.1 \mathrm{mbar}$ ) and handling under a protective gas atmosphere.

At room temperature, the polyelectrolytes are amorphous, highly viscous to glassy solids. In all cases, the polyelectrolytes show only one glasstransition temperature $\left(T_{\mathrm{g}}\right)$, which is clearly higher than $T_{\mathrm{g}}$ of unmodified polyglycerol. No melt transitions from a conceivable side chain crystallization were observed in any case.

The flexibility of the polyglycerol scaffold decreases gradually with an increasing degree of functionalization because of the repulsive interac- 
Table 3. $T_{\mathrm{g}}$ Values of the Polyelectrolytes and Polyglycerol

\begin{tabular}{|c|c|c|}
\hline & Polymer & $T_{\mathrm{g}}\left({ }^{\circ} \mathrm{C}\right)$ \\
\hline 1 & $\mathrm{PG}\left(\mathrm{C}_{2}-\mathrm{pyr}-\mathrm{Br}\right)_{1.0}$ & 41 \\
\hline 2 & $\mathrm{PG}\left(\mathrm{C}_{5}-\mathrm{pyr}-\mathrm{Br}\right)_{1.0}$ & 49 \\
\hline 3 & $\mathrm{PG}\left(\mathrm{C}_{7}-\mathrm{pyr}-\mathrm{Br}\right)_{1.0}$ & 40 \\
\hline 4 & $\mathrm{PG}\left(\mathrm{C}_{10}-\mathrm{pyr}-\mathrm{Br}\right)_{1.0}$ & 29 \\
\hline 5 & $\mathrm{PG}\left(\mathrm{C}_{5}-\mathrm{pyr}-\mathrm{Br}\right)_{0.3}$ & 9 \\
\hline 6 & $\mathrm{PG}\left(\mathrm{C}_{5}-\mathrm{pyr}-\mathrm{Br}\right)_{0.5}$ & 31 \\
\hline 7 & $\mathrm{PG}\left(\mathrm{C}_{5}-\mathrm{pyr}-\mathrm{Br}\right)_{0.7}$ & 40 \\
\hline 8 & $\mathrm{PG}\left(\mathrm{C}_{2}-1,2 \mathrm{DMI}-\mathrm{Br}\right)_{1.0}$ & 80 \\
\hline 9 & $\mathrm{PG}\left(\mathrm{C}_{5}-1,2 \mathrm{DMI}-\mathrm{Br}\right)_{1.0}$ & 37 \\
\hline 10 & $\mathrm{PG}\left(\mathrm{C}_{7}-1,2 \mathrm{DMI}-\mathrm{Br}\right)_{1.0}$ & 40 \\
\hline 11 & $\mathrm{PG}\left(\mathrm{C}_{10}-1,2 \mathrm{DMI}-\mathrm{Br}\right)_{1.0}$ & 26 \\
\hline 12 & PG $\left(\mathrm{C}_{2}-1,2 \mathrm{DMI}-\mathrm{TPPMS}\right)_{1.0}$ & 54 \\
\hline 13 & $\mathrm{PG}\left(\mathrm{C}_{5}-1,2 \mathrm{DMI}-\mathrm{TPPMS}\right)_{1.0}$ & 45 \\
\hline 14 & $\mathrm{PG}\left(\mathrm{C}_{7}-1,2 \mathrm{DMI}-\mathrm{TPPMS}\right)_{1.0}$ & 46 \\
\hline 15 & PG(C $\left.\mathrm{C}_{10}-1,2 \mathrm{DMI}-\mathrm{TPPMS}\right)_{1.0}$ & 39 \\
\hline 16 & Polyglycerol $\left(M_{\mathrm{n}}=6000 \mathrm{~g} / \mathrm{mol}\right)$ & -12 \\
\hline
\end{tabular}

tions of the cationic groups, and this results in an increase in $T_{\mathrm{g}}$, as shown in Figure 4 . The complete functionalization of the $\mathrm{OH}$ groups with alkylpyridinium groups $\left[\mathrm{PG}\left(\mathrm{C}_{5}-\mathrm{pyr}-\mathrm{Br}\right)_{1.0}\right]$ causes an enhancement of $T_{\mathrm{g}}$ by about $60^{\circ} \mathrm{C}$ in comparison with the unmodified hyperbranched polyglycerol.

The variation of the spacer length and the nature of the counterion have an influence on $T_{\mathrm{g}}$ as well. Using short alkyl spacers between the polyglycerol backbone and cationic groups leads to an increase in the ion density and a considerable decrease in the chain flexibility expressed by a high $T_{\mathrm{g}}$, as shown in Figure 5 for the imidazolium polyelectrolyte. An albeit less pronounced trend of a decrease in $T_{\mathrm{g}}$ with an increasing alkyl chain length has also been observed for the pyridinium polyelectrolyte.

An exchange of bromide counterions in $\mathrm{PG}\left(\mathrm{C}_{n^{-}}\right.$ 1,2-DMI-Br) ${ }_{1.0}$ by monosulfonated triphenylphosphine (TPPMS) lowers the influence of the spacer length on $T_{\mathrm{g}}$. The effect of the counterions on the polymer structure and $T_{\mathrm{g}}$ depends on the extent to which the cationic groups are shielded from one another, which is dependent on the polarizability and steric demand of the counterions. A possible explanation for the experimental findings is the formation of a closer ion pair with bromide ions in comparison with TPPMS due to their higher polarizability. This has a greater influence at decreasing spacer lengths. At higher spacer lengths, the higher steric demand of the TPPMS counterions leads to a more rigid structure and a higher $T_{\mathrm{g}}$ than that observed with bromide counterions.

\section{Thermal Stability}

The thermal stability of the polyelectrolytes $\mathrm{PG}\left(\mathrm{C}_{7}-\text { pyr-Br }\right)_{1.0}, \quad \mathrm{PG}\left(\mathrm{C}_{7}-1,2-\mathrm{DMI}-\mathrm{Br}\right)_{1.0}, \quad$ and $\mathrm{PG}\left(\mathrm{C}_{7}-1,2 \text {-DMI-TPPMS }\right)_{1.0}$ was investigated by thermogravimetric analysis (TGA) under a nitrogen atmosphere (Fig. 6). No significant weight loss was observed at temperatures below $200{ }^{\circ} \mathrm{C}$, and this confirmed the absence of low-molecularweight impurities or water in the samples. Whereas the unmodified polyglycerol had an onset decomposition temperature of about $350{ }^{\circ} \mathrm{C}$ (not shown in the figure), the polyelectrolytes were found to be less stable, degradation starting at $220-300{ }^{\circ} \mathrm{C}$.

The quaternization reaction of pyridine and imidazole derivatives with alkyl halogens is reversible at higher temperatures, the facility of cleavage of the alkyl groups from quaternary salts depending on the basicity of the quaternized group and the nucleophilicity of the counterion. ${ }^{37-39}$ Accordingly, the ion-exchanged polyelectrolyte $\mathrm{PG}\left(\mathrm{C}_{7}-1,2-\mathrm{DMI}-\mathrm{TPPMS}\right)_{1.0}$ (which is not capable of this reverse quaternization) has a higher thermal stability, which is close to the behavior of unfunctionalized polyglycerol with a degradation onset temperature of $300^{\circ} \mathrm{C}$.

\section{CONCLUSIONS}

Cationic hyperbranched polyelectrolytes can be prepared conveniently from polyglycerol in a one-pot reaction with $\omega$-bromoacyl chlorides $\mathrm{Cl}(\mathrm{C}=\mathrm{O})\left(\mathrm{CH}_{2}\right)_{n} \mathrm{Br}$ and pyridine or 1,2-dimethylimidazole. The density of the charged moieties,

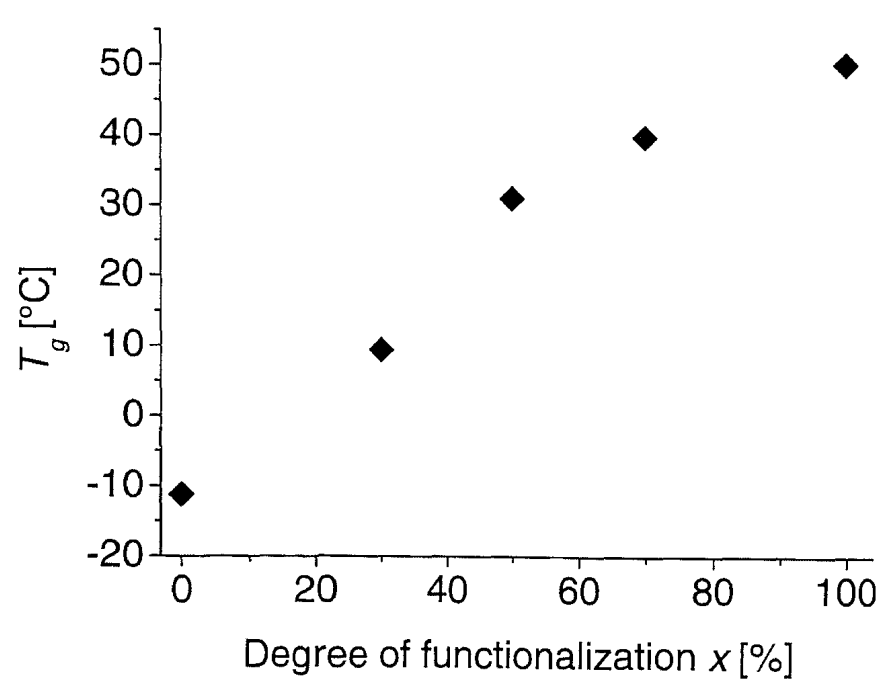

Figure 4. $T_{\mathrm{g}}$ as a function of the degree of functionalization $(x)$ for $\mathrm{PG}\left(\mathrm{C}_{5}-\mathrm{pyr}-\mathrm{Br}\right)_{x}$. 


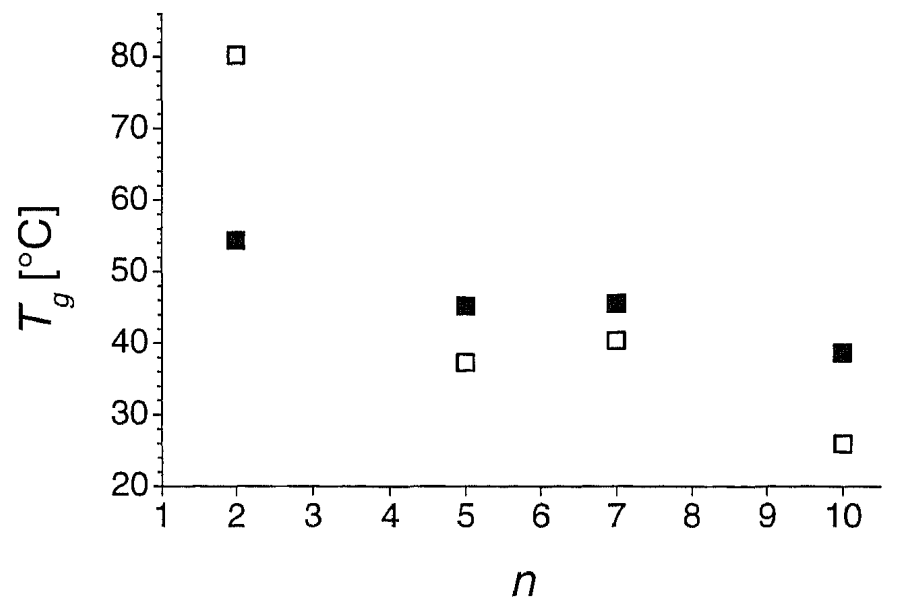

Figure 5. Influence of spacer length $n$ on $T_{\mathrm{g}}$ for imidazolium polyelectrolytes with ( $\square$ ) bromide and TPPMS counterions.

evidenced by $T_{\mathrm{g}}$, can be varied by either the degree of functionalization or spacer length $n$. The polyelectrolytes are thermally stable up to $>200{ }^{\circ} \mathrm{C}$.

\section{EXPERIMENTAL}

\section{Materials and General Procedures}

Hyperbranched polyglycerol was supplied by Hyperpolymers GmbH. ${ }^{31}$ Before the functionalization reactions, the polymeric material was dried at $0.1 \mathrm{mbar}$ at $80^{\circ} \mathrm{C}$ overnight; pyridine and 1,2dimethyleimidazole were distilled under argon. The $\omega$-bromoalkyl acid chlorides with spacer lengths of 2,7 , and $10 \mathrm{C}$ atoms were prepared by the reaction of the corresponding $\omega$-bromoalkyl carboxylic acid with thionyl chloride (excess $\mathrm{SOCl}_{2}, 80^{\circ} \mathrm{C}$, and $3 \mathrm{~h}$; yield $=75-85 \%$ after distillation at 0.1 mbar). KTPPMS was prepared by the method reported by Stelzer and coworkers ${ }^{40,41}$ from 4-(fluoro)benzenesulfonic acid chloride and diphenylphosphine (overall yield $=61 \%$; phosphine oxide $<3 \%$ from ${ }^{31} \mathrm{P}$ NMR). All other reagents were purchased from Aldrich or Fluka. For the purification of polyelectrolytes by dialysis, a benzoylated cellulose membrane with a nominal molecular weight cutoff of $1200 \mathrm{Da}$ (SigmaAldrich) was employed.

NMR spectra were recorded in methanol- $d_{4}$ at $298 \mathrm{~K}$ on a Bruker ARX 300 spectrometer operating at $300\left({ }^{1} \mathrm{H} \mathrm{NMR}\right)$ and $75.4 \mathrm{MHz}\left({ }^{13} \mathrm{C} \mathrm{NMR}\right)$. IR measurements were performed on a Bruker IFS 88 FTIR spectrometer equipped with a goldengate attenuated total reflection unit. DSC measurements were carried out on a PerkinElmer 7 series thermal analysis system in the temperature range of -50 to $+100{ }^{\circ} \mathrm{C}$ at a heating and cooling rate of $10 \mathrm{~K} / \mathrm{min}$. The reported data are second heats. Thermogravimetry was carried out on a Netzsch STA 409 instrument from 30 to $600{ }^{\circ} \mathrm{C}$ at a heating rate of $10 \mathrm{~K} / \mathrm{min}$ under a nitrogen atmosphere. The solution viscosities were determined in aqueous solutions and $0.1 \mathrm{M}$ aqueous $\mathrm{KBr}$ with a Lauda PVS 1 Ubbelohde dilution viscosimeter at $20^{\circ} \mathrm{C}$ with a capillary $0.53 \mathrm{~mm}$ in diameter.

\section{Synthesis of the Polyelectrolytes}

The general procedures for the polyelectrolyte syntheses are exemplified by the protocols employed for $\mathrm{PG}\left(\mathrm{C}_{2}-\mathrm{pyr}-\mathrm{Br}\right)_{1.0}, \quad \mathrm{PG}\left(\mathrm{C}_{5}-\right.$ pyr$\mathrm{Br})_{1.0}$, and $\mathrm{PG}\left(\mathrm{C}_{7}-1,2-\mathrm{DMI}-\mathrm{Br}\right)_{1.0}$ (for complete data, cf. ref. 26).

\section{$P G\left(C_{2}-p y r-B r\right)_{1.0}$}

To a solution of $2.54 \mathrm{~g}$ ( $34.4 \mathrm{mmol}$ of $\mathrm{OH}$ groups) of dried polyglycerol in $20 \mathrm{~mL}$ of NMP, $6.07 \mathrm{~g}$ (35.44 mmol) of 3-bromopropionyl chloride was added dropwise under an argon atmosphere. After the solution was stirred at $80{ }^{\circ} \mathrm{C}$ for $2.5 \mathrm{~h}$, $25 \mathrm{~mL}$ of freshly distilled pyridine was added. The clear mixture was stirred for an additional $15 \mathrm{~h}$ at $80^{\circ} \mathrm{C}$; during this time, the product precipitated. The obtained polyelectrolyte was purified by dialysis in a methanol solution, and this afforded the final purified product in a $78 \%$ overall yield.

${ }^{1} \mathrm{H}$ NMR (300 MHz, methanol- $\left.d_{4}, \delta\right): 9.24(2 \mathrm{H}$, pyr.), 8.68 (1H, pyr.), 8.20 ( $2 \mathrm{H}$, pyr.), $5.04\left[\mathrm{CH}_{2}-\right.$ pyr

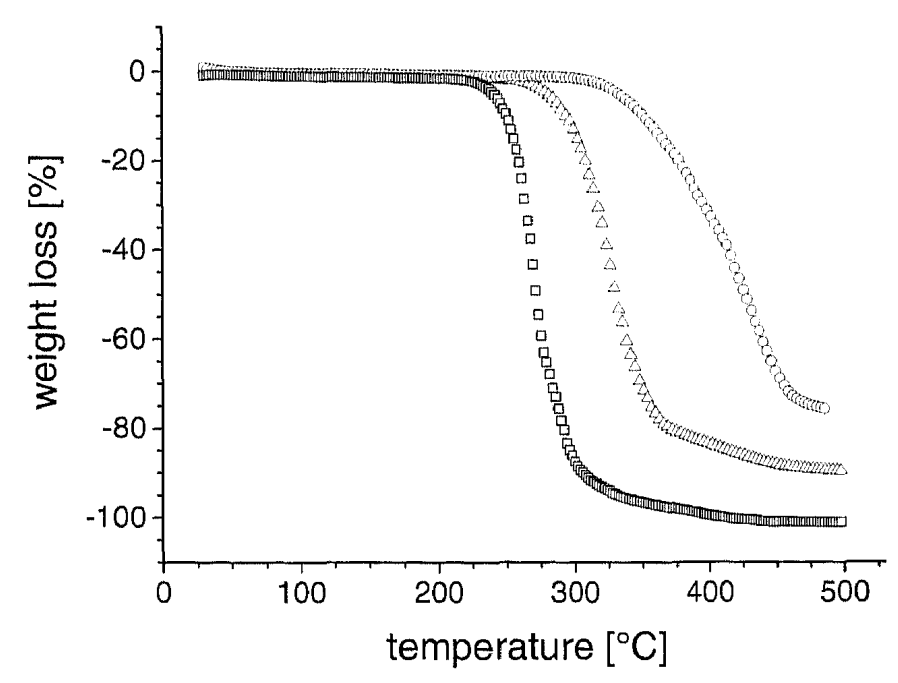

Figure 6. TGA of $(\square) \mathrm{PG}\left(\mathrm{C}_{7}-\mathrm{pyr}-\mathrm{Br}\right)_{1.0},(\triangle) \mathrm{PG}\left(\mathrm{C}_{7}-\right.$ 1,2-DMI-Br $)_{1.0}$, and (O) PG(C $C_{7}-1,2$-DMI-TPPMS $)_{1.0}$ under $\mathrm{N}_{2}$. 
and $\mathrm{PG}-\mathrm{CHO}(\mathrm{CO})], 4.5-3.2\left(\mathrm{PG} \mathrm{CH} / \mathrm{CH}_{2}\right), 3.33$ [2H, $\left.\mathrm{PG}-\mathrm{O}(\mathrm{CO}) \mathrm{CH}_{2}-\right] .{ }^{13} \mathrm{C}$ NMR $(75 \mathrm{MHz}$, methanol- $\left.d_{4}, \delta\right): 171.5-171.0(\mathrm{C}=\mathrm{O}), 147.2\left(\mathrm{CH}_{\text {pyr }}\right), 146.6$ $\left(\mathrm{N}^{+} \mathrm{CH}\right), 129.2\left(\mathrm{CH}_{\mathrm{pyr}}\right), 79.8\left(\mathrm{CH}_{\mathrm{PG}}\right), 75.7-66(\mathrm{PG}$ : $\left.\mathrm{CH} / \mathrm{CH}_{2}\right), 64.3\left[\mathrm{PG}-\mathrm{CH}_{2} \mathrm{O}(\mathrm{CO})\right], 58.2\left(\mathrm{~N}^{+} \mathrm{CH}_{2}-\right)$, $36.1\left[-(\mathrm{CO})-\mathrm{CH}_{2}-\right]$.

\section{$P G\left(C_{5}-p y r-B r\right)_{1.0}$}

Under an argon atmosphere, $4.49 \mathrm{~g}$ (60 mmol of $\mathrm{OH}$ groups) of dried polyglycerol was dissolved in $80 \mathrm{~mL}$ of freshly distilled pyridine. 6-Bromohexanoyl chloride (1.05 equiv) was added dropwise at $80^{\circ} \mathrm{C}$. Upon the addition of the acid chloride, the solution turned yellow. The reaction mixture was stirred at $80{ }^{\circ} \mathrm{C}$ for $48 \mathrm{~h}$. After cooling to room temperature, the residual pyridine was decanted. The viscous polymer was dissolved in methanol and precipitated by the pouring of the solution into a 10 -fold volume of acetone. The precipitated polyelectrolyte was purified by dialysis in a methanol solution, and this afforded the final product in a $90 \%$ yield.

${ }^{1} \mathrm{H}$ NMR (300 MHz, methanol- $\left.d_{4}, \delta\right): 9.18(2 \mathrm{H}$, pyr.), 8.65 (1H, pyr.), 8.19 (2H, pyr.), 5.14 [PG-CHO(CO)], $4.77\left(2 \mathrm{H},-\mathrm{CH}_{2}-\mathrm{N}^{+}\right), 4.5-3.2$ ( $\mathrm{PG} \mathrm{CH} / \mathrm{CH}_{2}$ ), 2.37 [2H, $\mathrm{PG}-\mathrm{O}(\mathrm{CO}) \mathrm{CH}_{2}-$ ], 2.09, 1.67, $1.47\left(2 \mathrm{H}\right.$, respectively, $\mathrm{CH}_{2}$ of alkyl spacer $)$. ${ }^{13} \mathrm{C}$ NMR (75 MHz, methanol- $d_{4}, \delta$ ): 174.6-174.2 $(\mathrm{C}=\mathrm{O}), \quad 146.9 \quad\left(\mathrm{CH}_{\mathrm{pyr}}\right), \quad 146.1 \quad\left(\mathrm{~N}^{+} \mathrm{CH}\right), \quad 129.6$ $\left(\mathrm{CH}_{\mathrm{pyr}}\right), 80.0\left(\mathrm{CH}_{\mathrm{PG}}\right), 75.6-67.2\left(\mathrm{PG}: \mathrm{CH} / \mathrm{CH}_{2}\right)$, $64.1 \quad\left[\mathrm{PG}-\mathrm{CH}_{2} \mathrm{O}(\mathrm{CO})\right], \quad 62.7 \quad\left(\mathrm{~N}^{+} \mathrm{CH}_{2}\right), \quad 34.8$ $\left(\mathrm{CO}-\mathrm{CH}_{2}\right), 32.2 / 26.6 / 25.1\left(\mathrm{CH}_{2}\right.$ of alkyl spacer $)$. Elem. ANAL. Calcd. for $\mathrm{C}_{1121} \mathrm{H}_{1603} \mathrm{~N}_{79} \mathrm{O}_{242} \mathrm{Br}_{79}$ $\left(26,370.88 \mathrm{~g} \mathrm{~mol}^{-1}\right): \mathrm{C}, 51.06 \% ; \mathrm{H}, 6.13 \% ; \mathrm{N}$, $4.20 \%$. Found: C, $51.89 \% ; \mathrm{H}, 6.36 \% ; \mathrm{N}, 4.32 \%$.

\section{$P G\left(C_{T}-1,2-D M I-B r\right)_{1.0}$}

Under an argon atmosphere, $3.0 \mathrm{~g}(40.5 \mathrm{mmol}$ of $\mathrm{OH}$ groups) of dried polyglycerol was dissolved in $35 \mathrm{~mL}$ of NMP. To the stirred solution, 1.05 equiv of 8-bromooctanoyl chloride was added, and the mixture was heated to $80{ }^{\circ} \mathrm{C}$ for $2-3 \mathrm{~h}$ until a homogeneous solution was formed. Then, $10 \mathrm{~mL}$ (112 $\mathrm{mmol}$ ) of 1,2-DMI was added, and the reaction mixture was stirred at $80^{\circ} \mathrm{C}$ for an additional 30-50 h. After cooling to room temperature, the precipitated polyelectrolyte was dissolved in methanol and reprecipitated by the pouring of the solution into a 10-fold volume of an acetone/ diethyl ether $(1: 1 \mathrm{v} / \mathrm{v})$ mixture. The precipitate was further purified by dialysis, which yielded the final product in an $85 \%$ yield.
${ }^{1} \mathrm{H}$ NMR $\left(300 \mathrm{MHz}\right.$, methanol- $\left.d_{4}, \delta\right): 7.60 / 7.53$ $(2 \mathrm{H}, \quad \mathrm{N}-\mathrm{CH}=\mathrm{C} H-\mathrm{N}), \quad 5.15 \quad[\mathrm{PG}-\mathrm{CHO}(\mathrm{CO})]$, $4.21\left(2 \mathrm{H},-\mathrm{CH}_{2}-\mathrm{N}^{+}\right), 4.5-3.4\left(\mathrm{PG} \mathrm{CH} / \mathrm{CH}_{2}\right), 3.87$ $\left(3 \mathrm{H}, \mathrm{N}-\mathrm{CH}_{3}\right), 2.69\left(3 \mathrm{H}, \mathrm{C}-\mathrm{CH}_{3}\right), 2.35[2 \mathrm{H}$, $\mathrm{PG}-\mathrm{O}(\mathrm{CO}) \mathrm{CH}_{2}-\mathrm{]}, 1.86 \quad\left(2 \mathrm{H}, \mathrm{CH}_{2}\right.$ of alkyl spacer), $1.62\left(2 \mathrm{H}, \mathrm{CH}_{2}\right.$ of alkyl spacer $), 1,40(6 \mathrm{H}$, $\mathrm{CH}_{2}$ of alkyl spacer). ${ }^{13} \mathrm{C} \mathrm{NMR} \mathrm{(75} \mathrm{MHz,} \mathrm{metha-}$ nol- $\left.d_{4}, \delta\right): 174.7-174.4(\mathrm{C}=\mathrm{O}), 145.8\left(C-\mathrm{CH}_{3}\right)$, $123.7 / 122.3(\mathrm{~N}-\mathrm{CH}=\mathrm{CH}-\mathrm{N}), 80.2-78.7\left(\mathrm{CH}_{\mathrm{PG}}\right)$, 74.5-69.4 (PG: $\mathrm{CH} / \mathrm{CH}_{2}$ ), 64.5 [PG- $\mathrm{CH}_{2} \mathrm{O}(\mathrm{CO})$ ], $49.5\left(\mathrm{~N}^{+} \mathrm{CH}_{2}\right), 35.6\left(\mathrm{~N}-\mathrm{CH}_{3}\right), 35.0\left(\mathrm{CO}-\mathrm{CH}_{2}\right)$, $30.8 / 30.0 / 27.2 / 26.0\left(\mathrm{CH}_{2}\right.$ of alkyl spacer $), 10.0$ $\left(\mathrm{C}-\mathrm{CH}_{3}\right)$.

Funding by the Deutsche Forschungsgemeinschaft (projects Me1388/2-1 to Me1388/2-3) is gratefully acknowledged. S. Mecking is in debt to the Fonds der Chemischen Industrie and to the Hermann Schnell Foundation for their financial support.

\section{REFERENCES AND NOTES}

1. (a) Fischer, M.; Vögtle, F. Angew Chem Int Ed Engl 1999, 38, 884-905; (b) Fischer, M.; Vögtle, F. Angew Chem 1999, 111, 934-955.

2. Bosman, A. W.; Janssen, H. M.; Meijer, E. W. Chem Rev 1999, 99, 1665-88.

3. (a) Hecht, S.; Fréchet, J. M. J. Angew Chem Int Ed Engl 2001, 40, 74-91; (b) Hecht, S.; Fréchet, J. M. J. Angew Chem 2001, 113, 76-94.

4. (a) Oosterom, G. E.; Reek, J. N. H.; Kamer, P. C. J.; van Leeuwen, P. W. N. M. Angew Chem Int Ed Engl 2001, 40, 1828-49; (b) Oosterom, G. E.; Reek, J. N. H.; Kamer, P. C. J.; van Leeuwen, P. W. N. M. Angew Chem 2001, 113, 1878-901.

5. Van Heerbeek, R.; Kamer, P. C. J.; van Leeuwen, P. W. N. M.; Reek, J. N. H. Chem Rev 2002, 102, 3717-3756.

6. Flory, P. J. J Am Chem Soc 1952, 74, 2718-2723.

7. Jikei, M.; Kakimoto, M. Prog Polym Sci 2001, 26, 1233.

8. Gao, C.; Yan, D. Prog Polym Sci 2004, 29, 183.

9. Yates, C. R.; Hayes, W. Eur Polym J 2004, 40, 1257.

10. Sunder, A.; Heinemann, J.; Frey, H. Chem-Eur J 2000, 6, 2499-2506.

11. Hölter, D.; Burgath, A.; Frey, H. Acta Polym 1997, 48, 30-35.

12. Turner, S. R.; Walter, F.; Voit, B. I.; Mourey, T. H. Macromolecules 1994, 27, 1611-1616.

13. Gong, A.; Liu, C.; Chen, Y.; Zhang, X.; Chen, C.; Xi, F. Macromol Rapid Commun 1999, 20, 492496.

14. Van Duijvenbode, R. C.; Rajanayagam, A.; Koper, G. J. M.; Baars, M. W. P. L.; de Waal, B. F. M.; Meijer, E. W. Macromolecules 2000, 33, 46-52. 
15. De Groot, D.; de Waal, B. F. M.; Reek, J. N. H.; Schenning, A. P. H. J.; Kamer, P. C. J.; Meijer, E. W.; van Leeuwen, P. W. N. M. J Am Chem Soc 2001, 123,8453 .

16. Van de Coevering, R.; Kuil, M.; Klein Gebbink, R. J. M.; van Koten, G. Chem Commun 2002, 1636-1637.

17. Mori, H.; Seng, D. C.; Lechner, H.; Zhang, M.; Müller, A. H. E. Macromolecules 2002, 35, 9270-9281.

18. Polyelectrolytes-Formation, Characterization and Application; Dautzenberg, H.; Jaeger, W.; Kötz, J.; Philipp, B.; Seidel, C.; Stscherbina, D., Eds.; Hanser: Munich, 1994.

19. Borkovec, M.; Koper, G. J. M. Macromolecules 1997, 30, 2151-2158.

20. Akari, S.; Schrepp, W.; Horn, D. Phys Chem Chem Phys 1996, 100, 1014-1016.

21. Welch, P.; Muthukumar, M. Macromolecules 1998, 31, 5892-5897.

22. Ramzi, A.; Scherrenberg, R.; Joosten, J.; Lemstra, P.; Mortensen, K. Macromolecules 2002, 35, 827-833.

23. Welch, C. F.; Hoagland, D. A. Langmuir 2003, 19, 1082-1088.

24. Borisov, O. V.; Daoud, M. Macromolecules 2001, 34, 8286-8293.

25. Schwab, E.; Mecking, S. Organometallics 2001, 20, 5504-5506.

26. Schwab, E. Ph.D. Thesis, Freiburg University, 2004.

27. Mecking, S.; Thomann, R. Adv Mater 2000, 12, 953-956.

28. Sablong, R.; Schlotterbeck, U.; Vogt, D.; Mecking, S. Adv Synth Catal 2003, 345, 333-336.

29. Sunder, A.; Mülhaupt, R. (Bayer AG).WO 00/ 37532, June 29, 2000.
30. Sunder, A.; Hanselmann, R.; Frey, H.; Mülhaupt, R. Macromolecules 1999, 32, 4240-4246.

31. www.hyperpolymers.com.

32. (a) Sunder, A.; Krämer, M.; Hanselmann, R.; Mülhaupt, R.; Frey, H. Angew Chem 1999, 111, 3758; (b) Sunder, A.; Krämer, M.; Hanselmann, R.; Mülhaupt, R.; Frey, H. Angew Chem Int Ed 1999, 38, 3552.

33. Sunder, A.; Bauer, T.; Mülhaupt, R.; Frey, H. Macromolecules 2000, 33, 1330.

34. Müh, E.Ph.D. Thesis, Freiburg University, 2001.

35. Menschutkin, J. J Russ Phys Chem Soc 1902, 34, 411.

36. Cohen, J.; Priel, Z. J Chem Phys 1988, 88, 71117116.

37. Awad, W. H.; Gilman, J. W.; Nyden, M.; Harris, R. H., Jr.; Sutto, T. E.; Callahan, J.; Trulove, P. C.; DeLong, H. C.; Fox, D. M. Thermochim Acta 2004, 409, 3-11.

38. Challis, B. C.; Butler, A. R. In The Chemistry of the Amino Group; Patai, S., Ed.; Interscience: New York, 1968; Chapter 6, p 277.

39. Goerdeler, J. In Houben-Weyl Methoden der Organischen Chemie, 4th ed.; Müller, E., Ed.; Thieme: Stuttgart, 1958; Vol. 11/2, Chapter 4, p 587.

40. (a) Herd, O.; Langhans, K. P.; Stelzer, O.; Weferling, N.; Sheldrick, W. S. Angew Chem 1993, 105, 1097; (b) Herd, O.; Langhans, K. P.; Stelzer, O.; Weferling, N.; Sheldrick, W. S. Angew Chem Int Ed 1993, 32, 1058.

41. Bitterer, F.; Herd, O.; Hessler, A.; Kühnel, M.; Rettig, K.; Stelzer, O.; Sheldrick, W. S.; Nagel, S.; Rösch, N. Inorg Chem 1996, 35, 4103. 